\title{
Hubungan Sense of Self dengan Kecenderungan Perilaku Bullying pada Siswa SMA di Jakarta
}

\author{
Isabela Rosari Irel \\ E-mail : isabela.rosari@gmail.com \\ Fakultas Psikologi \\ Universitas Katolik Atmajaya, Jakarta
}

\begin{abstract}
The purpose of this research is to find the correlation between sense of self and the tendency of high school student in Jakarta to bully others. Flurry and Ickes stated that sense of self is a personal perception about oneself, how people perceive themsleves and protect themselves to limit the effect of environment in their lives. This research is quantitative research that using questionnare to collect data. Researcher was using the translation of Adolescent Peer Relation Inventory (APRI) section A made by Praha to know the tendency of bullying in High School Student and the translation of Sense of Self Scale made by Flurry \& Ickes and revised by Culwell to measure sense of self of the bullied. Researcher collected data from $122 \mathrm{High}$ School students in Jakarta, with 79 (65\%) female students, 43 (35\%) male students, $23 \%$ in first year, $44 \%$ in second year, and $33 \%$ in third year. The research found that there is no correlation between sense of self and the tendency of high school student in Jakarta to bully others. There are a lot of reasons that can affect the results, such as the tendency to do conformity, the development and perception of teenagers, also the tendency to answer the questionnare with socially desirable response.
\end{abstract}

Key words: bullying, sense of self, the bullied, High School Student in Jakarta, bullying at school 


\section{PENDAHULUAN}

Bullying adalah segala bentuk penindasan atau intimidasi secara berulang-ulang, baik secara fisik, atau melalui kata-kata kepada orang yang lebih lemah di lingkungan sekolah, jalan ke sekolah atau pulang sekolah. Pelaku bullying biasanya lebih kuat baik secara sosial, perkataan, ataupun fisik dibandingkan korbannya (Hazler et.al. dalam Andersen, 2007). American Psychology Association (APA) menyatakan bahwa bullying merupakan perilaku agresif yang berulang-ulang dan dilakukan dengan tujuan membuat orang lain merasa tersakiti atau tidak nyaman. Bullying juga merupakan salah satu bentuk perilaku yang dapat melanggar hak asasi manusia (Andersen, 2007). Hal tersebut dapat terlihat dari tujuan bullying, yaitu menyakiti orang lain. Whitehouse (2006) mengatakan bahwa perilaku bullying biasanya muncul karena keinginan untuk menyebabkan orang lain merasa stress baik secara fisik ataupun psikologis, sehingga bullying adalah tindakan penindasan atau perilaku agresif yang terjadi berulang-ulang yang dilakukan kepada orang yang lebih kuat ke orang yang lebih lemah dan dapat menyebabkan masalah fisik maupun psikologis.

Bullying dapat terjadi di berbagai tempat yang terdapat interaksi sosial di dalamnya (Prasetyo, 2011). Hal tersebut karena bullying juga merupakan salah satu bentuk interaksi atau perilaku sosial. Bullying dilakukan oleh satu atau sekelompok orang terhadap orang lainnya (Sander \& Phye, 2004). Salah satu contoh kasus bullying adalah siswa SD yang sering mendapatkan hukuman fisik dari temannya di sekolahnya ataupun siswa yang sering diejek di sekolah (Yayasan Semai Jiwa Amini, 2008). Kasus tersebut memperlihatkan bahwa salah satu tempat terjadinya bullying adalah sekolah. Prasetyo (2011) dan Yayasan Semai Jiwa Amini (SEJIWA) menyatakan bahwa salah satu tempat terjadinya bullying adalah sekolah.

Undang-Undang Republik Indonesia no 20 tahun 2003 tentang sistem pendidikan nasional menyebutkan bahwa sekolah merupakan jenis pendidikan yang terstruktur dan berjenjang (pendidikan formal). Undang-Undang tersebut juga menjelaskan bahwa pendidikan adalah usaha sadar dan terencana untuk mewujudkan suasana belajar dan proses pembelajaran yang bertujuan untuk membuat peserta didik menjadi aktif mengembangkan potensi dirinya. Peserta didik diharapkan dapat memiliki kekuatan spiritual keagamaan, pengendalian diri, kepribadian, kecerdasan, sikap dan tindakan yang mulia, serta keterampilan yang berguna untuk dirinya sendiri, masyarakat, bangsa dan negara. Pendidikan juga diharapkan dapat berdasarkan Pancasila dan UndangUndang Dasar (UUD) 1945 yang berakar pada nilai-nilai agama, kebudayaan Indonesia, dan tanggap terhadap tuntutan zaman. Undang-Undang tersebut menunjukkan bahwa sekolah diharapkan dapat mewujudkan tujuan pendidikan karena sekolah merupakan salah satu jenis pendidikan.

Sekolah juga merupakan salah satu institusi yang bertanggung jawab dalam pembentukan karakter seseorang (Setyowati, 2009). Pembentukan karakter dilakukan dengan berbagai macam cara. Salah satunya adalah dengan memberikan mata pelajaran tertentu kepada siswa, misalnya mata pelajaran budi pekerti. Pembentukan karakter dan perilaku di sekolah tidak selalu berhasil, walaupun sekolah bertanggung jawab dan berusaha untuk membentuk karakter peserta didiknya. Hal tersebut dapat terlihat dari 
kecenderungan siswa SMA untuk tawuran atau sikap tidak sopan terhadap guru. Bentuk perilaku lainnya yang dapat terbentuk dan muncul di lingkungan sekolah adalah bullying (McKenzie; Stover dalam Lai, Ye, Chang, 2008).

Piskin (dalam Andersen, 2007) menyatakan bahwa bullying di sekolah merupakan permasalahan umum. Bullying merupakan suatu permasalahan karena dapat menimbulkan efek yang buruk bagi suasana sekolah. Bullying juga merupakan bentuk pelanggaran hak siswa di sekolah. Salah satu contoh pelanggarannya adalah mengambil hak murid untuk belajar di lingkungan yang aman tanpa merasa ketakutan (Piskin dalam Andersen, 2007). Furniss (dalam Andersen, 2007) juga mengatakan bahwa perilaku bullying di sekolah dapat menyebarkan pengalaman buruk seperti kesedihan, ketakutan, cemas, marah, stress, dan ketidakberdayaan.

Bullying di sekolah juga terjadi di Indonesia. Banyak kasus bullying yang telah terjadi di Indonesia. Komnas Perlindungan Anak (komnas PA) mencatat terdapat 139 kasus bullying yang terjadi di sekolah pada tahun 2011 (Triyuda, 2012). Hal tersebut baru merupakan kasus yang tercatat belum termasuk kasus yang tidak tercatat oleh komnas PA. Penelitian yang dilakukan SEJIWA (2008) di sejumlah kota besar di Indonesia, yaitu Jakarta, Yogyakarta, dan Surabaya juga memperlihatkan banyak kasus bullying terjadi di Indonesia. Secara umum, siswa dari setiap sekolah yang menjadi subjek dalam penelitian, mengakui bahwa terjadi kekerasan (baik secara verbal, fisik, maupun piskologis) di sekolah mereka. Siswa pada jenjang pendidikan sekolah menengah juga termasuk dalam siswa yang menyatakan bahwa terjadi tindakan bullying.di sekolah. Lebih dari 60\% siswa masingmasing di SMP dan SMA mengatakan bahwa terjadi kekerasan di sekolah mereka. Siswa SMA merupakan kelompok yang paling banyak merasa terjadi kekerasan di sekolah. Sekitar $67,9 \%$ siswa SMA merasa bahwa terjadi kekerasan di sekolah mereka. Hal tersebut juga dapat terlihat dari kasus-kasus bullying di sekolah yang terjadi di Indonesia. Banyak kasus bullying terjadi pada siswa di tingkat SMA (Cynantia, 2012).

Tindakan bullying yang terjadi di sekolah dapat menimbulkan banyak dampak bagi siswa yang terlibat di dalamnya. Salah satunya adalah siswa yang mengalami tindakan bullying melakukan bunuh diri. Bullying di sekolah merupakan salah satu penyebab bunuh diri pada anak-anak di Indonesia. Bunuh diri menjadi suatu tren yang memprihatinkan pada anak-anak Indonesia. Salah satu contoh kasus bunuh diri adalah seorang siswa yang gantung diri karena sering diejek gemuk (Soeriaatmadja, 2011). Olweus (1997) juga menyatakan bahwa korban bullying mempunyai pemikiran lebih banyak tentang bunuh diri dibandingkan teman sebayanya. Dampak lainnya yang mungkin terjadi adalah siswa menjadi lebih mudah stress atau siswa yang menjadi korban juga ikut menjadi pelaku terhadap anak lainnya (Toriq, 2012). Hal tersebut dapat menyebabkan kasus bullying kembali terulang.

Banyaknya kasus bullying di Indonesia dan dampak yang dapat terjadi, membuat masyarakat dan sekolah menjadi sadar serta peduli akan bahaya bullying, terutama jika melihat dampak yang dapat terjadi. Banyak masyarakat dan sekolah berusaha untuk mencegah atau mengurangi terjadinya bullying. Hal tersebut dapat terlihat dari adanya yayasan seperti yayasan Semai Jiwa Amini (SEJIWA), yang terus mengkampanyekan anti-bullying atau stop bullying. Sekolah 
juga sudah mulai berusaha untuk mengurangi atau mencegah tindakan bullying. Salah satu sekolah di Indonesia berusaha mencegah tindakan bullying dengan membuat seminar anti-bullying kepada siswanya. Seminar tersebut memberikan informasi tentang bullying sehingga siswa menjadi sadar dan tidak melakukan tindakan bullying (Napitupulu, 2012). Salah satu sekolah juga berusaha untuk mencegah tindakan bullying dengan memasang spanduk anti-bullying di sekolah (Kurniawan, 2012).

Cara lain yang dilakukan untuk mengurangi tindakan bullying adalah pemberian hukuman terhadap pelaku bullying (Priyatna, 2010). Hukuman yang diberikan dapat beragam. Salah satu contoh pemberian hukumannya adalah dengan mengenakan pakaian yang norak ke sekolah (Kristanti, 2013). Contoh hukuman lainnya adalah dipenjara (More, 2012). Guru juga memberikan hukuman kepada siswa yang mempunyai perilaku negatif (Valy, 2005). Hukuman yang diberikan guru pada siswa juga sering tidak mendidik (Suprihatin, 2013). Pemberian hukuman juga dapat memberikan dampak buruk bagi yang dihukum (Prasetyo, 2011). Pemberian hukuman bukanlah merupakan sebuah solusi. Penanganan yang lebih baik terhadap siswa yang mempunyai perilaku yang negatif adalah mencari tahu hal yang membuat siswa melakukan perilaku negatif sehingga dapat dibuat program yang baik untuk mengurangi perilaku tersebut (Valy, 2005). Beberapa penelitian berusaha untuk mencoba mengetahui halhal yang berhubungan dengan perilaku bullying. Kim (2004) menjelaskan bahwa faktor personal dan faktor lingkungan dapat mempengaruhi seseorang melakukan tindakan bullying.

Aronson, Akert, dan Wilson (2007) juga mendukung hal tersebut dengan menyatakan bahwa tingkatan pengaruh faktor eksternal dan internal setiap orang dalam mempengaruhi perilaku seseorang berbeda-beda. Salah satu cara untuk melihat pengaruh faktor internal dan eksternal dalam diri seseorang adalah dengan melihat sense of self (SoS) seseorang. SoS dapat membantu seseorang untuk melihat sejauh mana orang tersebut mengenal dirinya sendiri dan mempengaruhi perilakunya, serta sejauh mana faktor lingkungan dapat mempengaruhi dirinya (Flury \& Ickes, 2007).

Sense of self merupakan suatu perasaan bahwa seseorang menyadari dirinya sendiri, atau siapa dirinya (Vogels, 2012). SoS berhubungan dengan self esteem dan konsep diri (Andersen, 2007). Seseorang yang mengenal dirinya sendiri dengan baik (mempunyai SoS yang kuat) maka dapat menentukan sendiri aktivitas yang baik bagi dirinya tanpa banyak dipengaruhi oleh orang lain, sebaliknya seseorang yang mempunyai SoS yang lemah akan cenderung bergantung akan orang lain dalam pengambilan keputusan. Ia tidak mengenal dirinya sendiri dan tidak mengetahui secara pasti hal yang baik atau buruk bagi dirinya, sehingga ia memerlukan pendapat atau pengaruh dari orang lain (Flury \& Ickes, 2007).

SoS dapat membantu melihat faktor yang mempengaruhi seseorang untuk melakukan sesuatu. Jika seseorang yang mempunyai SoS kuat, maka orang tersebut mengetahui dengan jelas nilainilai yang dianut, mengetahui pilihannya, perilakunya, dan mempunyai pendapat sendiri. Orang tersebut mengetahui alasannya melakukan sesuatu. Faktor yang lebih banyak mempengaruhinya dalam melakukan sesuatu adalah dirinya sendiri (faktor internal). Ia tidak mudah dipengaruhi oleh orang lain atau lingkungannya dalam memutuskan 
melakukan sesuatu. Perilaku orang yang mempunyai SoS lemah bertolak belakang dengan orang yang mempunyai SoS kuat. Orang yang mempunyai SoS lemah tidak mengetahui dengan jelas mengenai dirinya sendiri sehingga akan lebih banyak dipengaruhi oleh orang lain atau lingkungan (faktor eksternal) karena ia belum mengetahui atau mengenal yang baik dan buruk bagi dirinya (Flurry \& Ickes, 2007).

Kernis (2000) juga mengatakan bahwa seseorang yang mempunyai SoS kuat cenderung merasa stabil dan aman. Mereka juga mempunyai keyakinan diri dan konsep diri yang jelas. Mereka cenderung melakukan sesuatu karena faktor internal. Mereka mengetahui goal mereka. Seseorang yang mempunyai SoS yang rendah atau lemah berbeda dengan mereka yang mempunyai SoS yang kuat. Mereka cenderung tidak stabil dan melakukan sesuatu karena faktor eksternal. Culwell (2008) menyatakan bahwa SoS dapat mempengaruhi atau mempunyai hubungan dengan partisipasi dalam aktivitas atau kegiatan sosial seseorang. Salah satu hal yang mungkin dapat mempengaruhi kecenderungan melakukan kegiatan sosial bullying pada siswa SMA adalah SoS.

Siswa-siswa SMA umumnya masuk dalam kategori remaja. Remaja adalah orang-orang yang masuk dalam kategori usia 10-17 tahun. Erikson mengatakan bahwa pada masa tersebut remaja masuk dalam tahapan identity vs identity confusion. Remaja mulai berusaha untuk mencari jati dirinya. Mereka mulai mempertanyakan tentang diri mereka sendiri, yang ingin mereka lakukan, dan yang lainnya. Secara tidak langsung, mereka juga sedang membentuk SoS dalam diri mereka. Mereka dalam proses mencari dan mengenal diri mereka sendiri. Ketika remaja berhasil mengatasi konflik- konflik dalam diri mereka yang berkaitan dengan identitas diri, maka mereka akan membentuk SoS yang baru dan bisa diterima (Santrock, 2009).

SoS remaja merupakan sesuatu yang rapuh. Hal tersebut disebabkan karena biasanya remaja cenderung ingin merasa diterima dan rasa diterima tersebut merupakan hal yang penting bagi mereka (Karcher dalam Andersen, 2007). Remaja dapat melakukan berbagai macam hal agar dapat diterima oleh teman atau kelompok temannya (peer), termasuk tindakan kiriminal, seperti mencuri (Santrock, 2009). Peer memegang pengaruh penting dalam diri mereka. Mereka perlu untuk merasa diterima oleh teman-temannya (Kim, 2004). Hal tersebut yang menyebabkan SoS remaja cenderung sesuatu yang rapuh karena masih dipengaruhi oleh rasa ingin diterima oleh kelompok bukan karena keinginan mereka sendiri. Keinginan untuk merasa diterima dapat menyebabkan remaja cenderung mengikuti keinginan atau kemauan dari peer mereka (konformitas) (Aronson, et.al., 2007), termasuk ketika peer melakukan hal yang tidak sesuai.

Penjelasan di atas memperlihatkan bahwa bullying di sekolah banyak terjadi pada siswa SMA di Jakarta. Bullying merupakan suatu masalah yang perlu diselesaikan untuk mengurangi dampak negatif bagi setiap orang yang terlibat. Berbagai cara dapat dilakukan untuk menanggulangi hal tersebut. Salah satu cara yang dapat dilakukan adalah dengan mengetahui hal-hal yang mempengaruhi seseorang melakukan tindakan bullying. Faktor yang dapat mempengaruhi seseorang melakukan tindakan bullying adalah faktor internal dan eksternal. Pengaruh kedua faktor tersebut terhadap seseorang dapat dilihat melalui sense of self orang tersebut. Penelitian yang dilakukan Culwell (2008) memperlihatkan 
bahwa SoS dapat mempengaruhi aktivitas atau perilaku sosial seseorang. Siswa SMA merupakan masa-masa pembentukan SoS. SoS pada siswa SMA juga cenderung rapuh. Remaja juga dapat melakukan berbagai macam hal agar dapat diterima oleh teman atau kelompok temannya (peer), termasuk tindakan kiriminal, seperti mencuri (Santrock, 2009). Hal tersebut membuat peneliti tertarik untuk meneliti apakah SoS seseorang juga mempunyai hubungan dengan kecenderungan bullying siswa SMA di Jakarta.

\section{METODE}

Partisipan

Penelitian ini merupakan penelitian yang menggunakan metode kuantitatif korelasional, dengan populasi siswa SMA di Jakarta. Pengambilan sampling dengan menggunakan teknik hapazhard atau convenience sampling. Peneliti akan mengunjungi beberapa sekolah SMA di Jakarta dan membagikan kuesioner kepada siswa yang ditemui oleh peneliti. Siswa yang akan mendapatkan kesempatan mengisi kuesioner hanya siswa yang ditemui oleh peneliti. Probabilitas siswa yang bertemu dengan peneliti dalam mengisi kuesioner lebih besar dibandingkan yang tidak bertemu dengan peneliti. Jumlah populasi dari penelitian ini di atas dari 10.000 (Dinas Pendidikan, 2010) sehingga jumlah sampel minimal yang diperlukan adalah 119. Hal tersebut didasarkan pada tabel perhitungan yang dilakukan oleh Bartlet, Kotrlik, \& Higgins (2001) untuk populasi 10.000 dengan margin of error .03 dan alpha .05. Penelitian ini menggunakan 122 sampel.

\section{Alat Ukur}

Alat ukur yang dipakai untuk pengambilan data dalam penelitian ini adalah terjemahan Sense of Self Scale dan terjemahan dari Adolescent Peer Relations Instrument (APRI) seksi A. Peneliti menggunakan kuesioner hasil translate yang mengacu pada Sense of Self Scale (SoSS) yang dibuat oleh Flurry \& Ickes (2007) dan direvisi dalam Culwell (2008). Kuesioner ini terdiri dari 18 pernyataan atau item. Pernyataan tersebut dibuat berdasarkan empat aspek atau domain yang terdapat pada orang yang mempunyai SoS yang lemah (Flurry \& Ickes, 2007), yaitu a) rasa kurang mengenal diri sendiri, b) perubahan yang cepat pada perasaan, pendapat, dan nilai yang dianut, c) kecenderungan untuk merasa bingung membedakan perasaan, pemikiran, dan perspektif diri sendiri dengan orang lain, d) perasaan keberadaan di dunia yang lemah. Pernyataan yang mengacu pada aspek kurangnya rasa pengenalan diri sendiri adalah nomor 2, 5, $8,10,13,14$. Pernyataan yang dibuat untuk melihat aspek perubahan yang cepat pada perasaan, pendapat, dan nilai yang dianut adalah 1, 9, 15. Pernyataan nomor $3,11,12,15$ dibuat untuk melihat aspek kecenderungan merasa bingung membedakan perasaan, pemikiran, dan perspektif sendiri dengan orang lain. Pernyataan 4, 6, 7 dibuat untuk melihat aspek merasa bahwa keberadaan di dunia lemah. Sedangkan untuk melihat kecenderungan perilaku bullying pada siswa SMA, peneliti akan menggunakan kuesioner terjemahan yang mengacu pada Adolescent Peer Relations Instrument (APRI) seksi A (Parada dalam Hamburger, et.al., 2011). Kuesioner ini terdiri dari dua seksi atau baterai tes, yaitu seksi A yang berkaitan dengan perilaku melakukan tindakan bullying (pelaku bullying) dan seksi B yang berkaitan dengan mendapatkan perilaku bullying (korban bullying). Masing-masing seksi terdiri dari 18 item. Penelitian ini lebih 
berfokus pada perilaku bullying, sehingga peneliti menggunakan hasil translate APRI seksi A, seperti pada George, Ayodele, Raheem, \& Bidemi (2013) dan George, Adeoye, Ayodele, \& Raheem (2013).

Kuesioner APRI seksi A terdiri dari 18 item yang dibuat berdasarkan 3 tipe bullying, yaitu verbal bullying, physical bullying, dan social bullying. Item yang menggambarkan verbal bullying adalah item $1,3,5,7,10$ dan 14. Item yang menggambarkan physical bullying adalah item $2,6,9,12,15$, dan 16 . Item sisanya yaitu, $4,8,11,13,17$, dan 18 menggambarkan social bullying. Kuesioner tersebut terdiri juga terdiri dari enam skala respon yaitu 1. tidak pernah, 2 . kadang-kadang 3.satu atau dua kali sebulan, 4. satu kali seminggu, 5. beberapa kali seminggu, 6. setiap hari. Responden diminta untuk melingkari skala yang sesuai dengan respon mereka. Skoring akan dilakukan dengan menjumlahkan respon mereka terhadap setiap item. Jumlah skor tersebut akan menentukan intensitas perilaku bullying yang biasanya dilakukan oleh responden.

\section{Uji Validitas}

Uji validitas yang dilakukan adalah dengan melihat item total correlation, yaitu skor setiap item dikorelasikan dengan skor total yang sudah dikurangi skor item yang akan dikorelasi. Teknik korelasi akan menggunakan pearson product moment. Pengujian validitas akan menggunakan program SPSS 21.00. Item dapat dikatakan valid jika hasil korelasinya lebih besar atau sama dengan 0,3 (Kaplan \& Sacuzzo, 2009)

\section{Uji Reliabilitas}

Kaplan dan Sacuzzo (2009) menyatakan bahwa reliabilitas yang baik bagi alat tes adalah di atas 0.70 . Kedua alat tes yang akan dipakai mempunyai reliabilitas yang baik atau tinggi karena berada di atas 0.70 , yaitu 0.783 untuk SoSS dan 0.864 untuk APRI section A. Kuesioner SoSS pada versi aslinya mempunyai reliabilitas 0.892 , sedangkan untuk APRI section A versi asli mempunyai reliabilitas 0.92 .

\section{Teknik Analisis Data}

Penelitian akan menggunakan teknik korelasi. Teknik analisa menggunakan teknik korelasi karena ingin melihat hubungan antara dua variabel, yaitu SoS dengan kecenderungan melakukan bullying. Teknik korelasi yang akan dilakukan adalah teknik korelasi menggunakan Pearson product moment.

\section{HASIL}

Subjek dalam penelitian ini berjumlah 122 orang. Subjek dari penelitian ini berjenis kelamin laki-laki dan perempuan. Jumlah subjek laki-laki adalah 43 orang (sekitar 35\%) dan jumlah subjek perempuan adalah 79 orang (sekitar 65\%). Semua subjek dalam penelitian ini sesuai dengan kriteria pemilihan subjek, yaitu merupakan siswa SMA di Jakarta dan merupakan pelaku bullying di sekolah. Subjek penelitian berasal dari jenjang kelas yang beragam, mulai dari kelas 1 SMA hingga 3 SMA. Jumlah siswa kelas 1 SMA yang menjadi subjek dari penelitian ini adalah 28 orang (sekitar 23\%). Jumlah siswa kelas 2 SMA yang menjadi subjek dari penelitian ini adalah 54 orang (sekitar 44\%). Jumlah siswa kelas 3 SMA yang menjadi subjek penelitian ini adalah 40 orang (sekitar $33 \%$ ). Setiap siswa yang menjadi subjek penelitian merupakan pelaku bullying di sekolah karena mempunyai nilai APRI section A di atas 18. Parada dalam Hamburger, et.al. (2011) menyatakan bahwa remaja dapat dikatakan bukan 
merupakan pelaku bullying jika mempunyai nilai APRI section sebesar 18.

Tabel 1. Gambaran Jenis Kelamin Subjek Penelitian

\begin{tabular}{lcc}
\hline Jenis & $\mathrm{N}$ & $\%$ \\
Kelamin & & \\
\hline Laki-laki & 42 & $35 \%$ \\
Perempuan & 77 & $65 \%$ \\
\hline
\end{tabular}

Tabel 2. Gambaran Jenjang Kelas Subjek Penelitian

\begin{tabular}{lll}
\hline $\begin{array}{l}\text { Jenjang } \\
\text { Kelas }\end{array}$ & $\mathrm{N}$ & $\%$ \\
\hline 1 SMA & 28 & $23 \%$ \\
2 SMA & 54 & $44 \%$ \\
3 SMA & 40 & $33 \%$ \\
\hline
\end{tabular}

Hasil kuesioner APRI section A mempunyai nilai total pada masingmasing subjek yang beragam mulai dari 20 hingga 44. Rata-rata nilai total subjek adalah sekitar 30.43 dengan standar deviasi 5.61. Distribusi nilai pada kuesioner ini termasuk distribusi normal karena $p$-value dari Saphiro-Wilk yang telah dihitung di atas 0.05 (0.06). Ghazemi \& Zahediasl (2012) menyatakan bahwa Saphiro-Wilk adalah salah satu teknik pengujian normalitas yang mempunyai power yang kuat. . Beberapa peneliti menyatakan bahwa Saphiro-Wilk merupakan pilihan terbaik untuk menguji normalitas. Salah satunya adalah Razali \& Wah (2011). Penelitian yang dilakukan oleh Razali \& Wah (2011) memperlihatkan bahwa Saphiro Wilk merupakan teknik uji normalitas yang mempunyai power yang paling kuat dibandingkan uji tes normalitas lainnya (Kolmogorov-Smirnov, Lilliefors, dan Anderson-Darling Tests). Penelitian dengan jumlah sampel 50-2000 dapat menggunakan Saphiro-Wilk untuk pengujian normalitas. Sebuah grafik atau distribusi dapat dikatakan normal jika mempunyai $p$-value di atas 0.05 (Ghazemi $\&$ Zahediasl, 2012). Nilai p-value APRI dalam penelitian ini adalah 0.06 sehingga dapat disimpulkan bahwa distribusi nilai APRI merupakan distribusi normal.

Nilai total domain verbal bullying pada masing-masing subjek juga beragam, yaitu mulai dari 7 hingga 23 dengan ratarata 14.09. Nilai total domain social bullying pada masing-masing subjek mulai dari 6 hingga 14 dengan rata-rata 8.11. Nilai total domain physical bullying mulai dari 6 hingga 15 dengan rata-rata 8.27. Cara untuk mendapatkan nilai total adalah dengan dengan menambahkan semua nilai masing-masing domain.

Hasil di atas memperlihatkan bahwa subjek penelitian ini paling banyak melakukan verbal bullying. Kecenderungan subjek penelitian yang lebih besar melakukan verbal bullying dapat disebabkan karena jumlah subjek penelitian yang berjenis kelamin perempuan. James (2010) menyatakan bahwa perempuan lebih banyak melakukan verbal bullying, sedangkan laki-laki cenderung lebih melakukan physical bullying. Macklem (2003) juga mendukung pernyataan tersebut serta menambahkan bahwa walaupun laki-laki lebih cenderung melakukan physical bullying mereka juga sering melakukan verbal bullying. Penelitian yang dilakukan Darmawan (2010) juga memperlihatkan bahwa kecenderungan tersebut juga berlaku di Indonesia. Hasil penelitiannya memperlihatkan bahwa siswa perempuan cenderung melakukan tindakan bullying dengan mengejek atau memanggil seseorang dengan sebutan tertentu dibanding laki-laki. Gambaran umum hasil penelitian ini memperlihatkan bahwa jumlah subjek perempuan lebih banyak (65\%) dibandingkan jumlah subjek lakilaki (35\%), Banyaknya subjek perempuan tersebut dapat mempengaruhi 
kecenderungan perilaku bullying pada penelitian ini, yaitu verbal bullying.

Tabel 3. Gambaran Hasil Kuesioner APRI section A

\begin{tabular}{llll}
\hline $\begin{array}{l}\text { Domain } \\
\text { dan Total }\end{array}$ & $\begin{array}{l}\text { Mini- } \\
\text { mum }\end{array}$ & $\begin{array}{l}\text { Maksi- } \\
\text { mum }\end{array}$ & $\begin{array}{l}\text { Rata- } \\
\text { rata }\end{array}$ \\
\hline $\begin{array}{l}\text { Verbal } \\
\text { Bullying }\end{array}$ & 7 & 23 & 14.09 \\
$\begin{array}{l}\text { Social } \\
\text { Bullying }\end{array}$ & 6 & 14 & 8.11 \\
$\begin{array}{l}\text { Physical } \\
\text { Bullying }\end{array}$ & 6 & 15 & 8.27 \\
\hline Total & 20 & 44 & 30.43 \\
\hline
\end{tabular}

Nilai hasil kuesioner SoSS masingmasing subjek mempunyai range dari 30 hingga 64. Rata-rata nilai subjek adalah 46.78 dengan dengan standar deviasi 7.65. Seseorang dapat dikatakan mempunyai SoS yang rendah jika mempunyai nilai di atas 50.6. Nilai minimal tersebut didapatkan dari menjumlahkan nilai ratarata dengan setengah dari nilai standar deviasi (Cuperman, Robinson, \& Ickes, 2012). Seseorang dapat dikatakan mempunyai SoS yang tinggi jika mempunyai nilai dibawah atau sama dengan 42.95. Nilai tersebut didapatkan dari mengurangkan nilai rata-rata dengan setengah dari nilai standar deviasi (Cuperman, et.al., 2012). Subjek dalam penelitian ini yang mempunyai SoS tinggi dan SoS rendah masing-masing berjumlah 38 dan 39 subjek. Hasil kuesioner ini mempunyai distribusi normal karena nilai p-value berdasarkan perhitungan SaphiroWilk adalah 0.258 (di atas 0.05).

Peneliti ingin melihat hubungan antara SoS dengan kecenderungan melakukan bullying pada siswa SMA di Jakarta dengan menggunakan pearson product moment. Peneliti membandingkan antara hasil total skor SoS dengan hasil total skor APRI. Hasil korelasi kedua variabel tersebut adalah -0.042. Hasil perhitungan korelasi tersebut memperlihatkan bahwa tidak terdapat korelasi yang signifikan antara SoS dan kecenderungan perilaku bullying pada siswa SMA di Jakarta. Tabel critical value pearson correlation memperlihatkan bahwa nilai yang dibutuhkan untuk mengatakan bahwa dua variabel berkorelasi jika menggunakan subjek 122 adalah jika lebih besar dari 0.178. Kedua variabel dapat juga dikatakan berkorelasi jika mempunyai nilai signifikansi atau pvalue di bawah 0.05 , sedangkan pada penelitian ini diperoleh nilai 0.647 (di atas $0.05)$

\section{DISKUSI}

Hasil penelitian menunjukkan bahwa tidak terdapat hubungan yang signifikan antara SoS dengan kecenderungan perilaku bullying pada siswa SMA di Jakarta.Salah satu alasan yang mungkin dapat menyebabkan korelasi yang tidak signifikan adalah remaja masih dipengaruhi dan terpengaruh oleh banyak faktor dalam melakukan sesuatu, seperti emosi, peer, atau persepsi mereka sendiri bukan hanya berdasarkan satu faktor saja. Remaja juga masih masuk dalam tahap pencarian identitas sehingga mereka masih cenderung mencoba dan bereksperimen dengan berbagai hal (Santrock, 2009). Mereka cenderung masih suka berubah-ubah dalam perilaku maupun preferensi mereka, seperti pada saat ini mereka cenderung menyukai fashion yang rapi, tetapi pada saat yang lain mereka dapat berubah dan menjadi menyukai fashion yang berantakan. Hal tersebut memperlihatkan bahwa perilaku remaja masih cenderung berubah-ubah dan dapat disebabkan oleh berbagai faktor.

Salah satu hal yang dapat mempengaruhi remaja adalah adolescent egocentrism. Adolescent egocentrism 
adalah perasaan remaja merasa menyadari dirinya sendiri. Adolescent egocentrism mempunyai 2 komponen utama, yaitu imaginary audience dan personal fable. Imaginary audience adalah remaja merasa bahwa orang lain tertarik pada diri remaja tersebut atau selalu memperhatikan remaja tersebut. Personal fable adalah merasa bahwa dirinya unik dan tidak terkalahkan. Perasaan tersebut membuat mereka merasa bahwa tidak ada orang yang mengerti dan memahami yang mereka rasakan (Santrock, 2009).

Perasaan bahwa remaja menyadari diri mereka sendiri dan tidak ada yang mengerti serta memahami mereka akan mempengaruhi remaja itu sendiri. Remaja dapat melakukan perilaku tertentu karena dipengaruhi oleh pemikiran tersebut, seperti menjadi (lebih sering) menulis buku harian. Hal tersebut memperlihatkan bahwa tidak menutup kemungkinan perilaku bullying juga dapat muncul karena pemikiran tersebut. Mereka merasa dan ingin agar diperhatikan oleh orang lain sehingga mereka dapat berusaha mendapatkan hal tersebut melalui perilaku mereka (Santrock, 2009). Pemikiran tersebut juga dapat mempengaruhi SoS remaja sehingga dapat atau mempunyai kemungkinan membuat remaja mempunyai penilaian yang berbeda terhadap SoS mereka. Pemikiran tersebut dapat mempengaruhi SoS remaja itu sendiri karena beberapa aspek dari SoS yang lemah adalah merasa kurang mengerti dirinya sendiri dan merasa keberadaan di dunia ini lemah.

Remaja yang merasa bahwa ia menyadari dirinya sendiri maka remaja akan cenderung mendapatkan nilai yang rendah pada aspek kurang mengerti dirinya sendiri padahal aspek tersebut merupakan aspek yang mempunyai item paling banyak (6 item) dan penting. Hasil penelitian mendukung kemungkinan tersebut. Hasil penelitian memperlihatkan bahwa aspek kurang mengenal dirinya sendiri mempunyai nilai rata-rata yang paling kecil dibandingkan ketiga aspek yang lainnya, yaitu sekitar 329 sedangkan rentang nilai rata-rata aspek yang lain mulai dari 343 hingga 412. Hal tersebut memperlihatkan bahwa perasaan mengenal atau menyadari dirinya sendiri dapat mempengaruhi SoS seseorang, termasuk remaja. Persepsi remaja terhadap dirinya sendiri dapat mempengaruhi SoS remaja tersebut. Remaja merasa bahwa ia menyadari hal yang berkaitan dengan dirinya sendiri, seperti hal yang ingin dilakukannya padahal perasaan tersebut bisa saja hanya merupakan persepsi dari remaja itu sendiri.

Hal lain yang mungkin dapat mempengaruhi perilaku dan hasil SoS adalah personal fable. Remaja merasa bahwa dirinya unik, tidak terkalahkan, dan bahwa tidak ada yang mengerti serta memahami diri mereka. Mereka bahkan dapat membuat cerita fantasi tentang diri mereka sendiri agar memperoleh rasa keunikan mereka. Perasaan tidak terkalahkan membuat remaja merasa bahwa mereka kebal terhadap bahaya dan membuat remaja menjadi melakukan berbagai hal yang berbahaya, seperti penggunaan narkoba, rokok, ataupun kenakalan remaja (Santrock, 2009). Hal tersebut memperlihatkan bahwa perasaan tersebut juga mempunyai kemungkinan dapat mempengaruhi perilaku bullying pada remaja. Mereka merasa bahwa mereka tidak terkalahkan dan tidak takut akan bahaya atau dampak akan membully orang lain sehingga mereka melakukan perilaku bullying tersebut.

Perasaan tersebut juga dapat mempengaruhi aspek merasa bahwa keberadaan di dunia ini lemah dalam SoS. Salah satu item dalam aspek tersebut adalah saya sering berpikir apakah orang 
dapat memahami saya. Perasaan tidak yakin dalam diri remaja bahwa orang lain dapat memahami mereka dapat dipengaruhi karena merasa bahwa orang lain tidak mengerti mereka sehingga dapat mempengaruhi juga respon remaja menanggapi pernyataan tersebut. Pernyataan tersebut merupakan item kedua yang mempunyai nilai yang paling tinggi, yaitu 459. Hal tersebut juga dapat berdampak dalam penilaian aspek merasa keberadaan diri di dunia lemah. Aspek tersebut merupakan aspek yang mempunyai nilai rata-rata tertinggi kedua, yaitu 380. Penilaian tersebut juga dapat mempengaruhi hasil penilaian SoS remaja itu sendiri.

Perkembangan otak remaja juga dapat menjadi salah satu faktor yang mempengaruhi perilaku dan hasil SoS remaja. Santrock (2009) menyatakan bahwa bagian otak yang sedang berkembang pesat pada masa remaja adalah amigdala. Amigdala adalah bagian otak yang mengatur emosi seseorang, seperti marah. Hal tersebut membuat perilaku remaja cenderung dipengaruhi oleh emosi. Mereka cenderung melakukan sesuatu karena dipengaruhi oleh emosi. Hal tersebut juga dapat menjadi alasan banyak remaja melakukan kenakalan remaja.

Perkembangan otak tersebut dapat mempengaruhi perilaku dan perasaan remaja. Remaja jadi cenderung melakukan sesuatu sesuai perasaan atau emosi mereka pada saat tersebut. Hal tersebut dapat menyebabkan perilaku remaja dapat berubah-ubah tergantung dari emosi atau perasaan mereka. Emosi yang terus berubah dan berdampak pada perilaku remaja tersebut dapat mempengaruhi aspek yang kedua, yaitu perubahan yang cepat pada perasaan, pendapat, dan nilai yang dianut dalam SoSS. Perubahan yang cepat pada perasaan, pendapat, dan nilai yang dianut tersebut dapat dipengaruhi karena perkembangan salah satu bagian otak remaja, yaitu amigdala.

Perkembangan amigdala tersebut yang mungkin dapat mempengaruhi emosi remaja, yang berdampak pada kehidupan remaja tersebut, seperti perilaku atau pandangan remaja. Hal tersebut juga memperlihatkan bahwa kebanyakan remaja akan mengalami perubahan emosi secara cepat karena amigdala kebanyakan remaja akan berkembang, maka remaja seharusnya cenderung memperoleh nilai yang tinggi pada aspek perubahan yang cepat pada perasaan, pendapat, dan nilai yang dianut dalam SoSS. Hasil penelitian memperlihatkan hal tersebut. Aspek kedua dalam SoSS ini merupakan aspek yang mempunyai nilai rata-rata yang paling tinggi di antara ketiga aspek yang lainnya, yaitu 412. Salah satu item pada aspek ini juga merupakan item dengan nilai tertinggi, yaitu 534. Nilai item ini berbeda 75 nilai dengan item yang mempunyai nilai tertinggi kedua dan mempunyai perbedaan nilai yang cukup tinggi bandingkan sisa item lainnya yang hanya mempunyai nilai antara 261 hingga 406. Item tersebut adalah pernyataan yang menyatakan bahwa subjek penelitian berharap lebih konsisten terhadap perasaannya. Kebanyakan subjek juga memberikan respon sangat setuju dengan pernyataan tersebut, berarti banyak remaja merasa bahwa perasaannya tidak konsisten sehingga berharap lebih konsisten terhadap perasaan mereka.

Hal lain yang mungkin dapat mempengaruhi perilaku dan SoS remaja adalah kecenderungan untuk melakukan konformitas. Remaja sedang berada dalam tahap mudah dipengaruhi oleh kelompok atau peer. Mereka lebih melakukan konformitas dibandingkan masa kanakkanak (Santrock, 2009). Hal tersebut dapat membuat mereka cenderung melakukan 
perilaku yang dilakukan kelompok serta mengikuti atau mempercayai aturan, nilai, atau kepercayaan dalam kelompok. Salah satu contoh perilaku yang dapat dilakukan karena kelompok adalah perilaku bullying. Levianti (2008) menyatakan bahwa konformitas berhubungan dengan kecenderungan perilaku bullying pada remaja.

Hal lain yang dapat diikuti oleh remaja selain perilaku dalam kelompok adalah aturan, nilai, atau kepercayaan kelompok dalam kehidupan sehari-hari dan menganggap bahwa aturan, nilai, atau kepercayaan tersebut adalah hal yang benar padahal belum tentu hal yang benar, seperti kepercayaan bahwa ketika seseorang berbuat salah maka ia harus dikucilkan (Aronson, et.al., 2007). Hal tersebut menunjukkan bahwa kepercayaan atau nilai yang dianut oleh remaja belum tentu merupakan kepercayaan atau nilai yang sebenarnya mereka anut sendiri, tetapi mereka tetap menjadikan patokan dan menganggap bahwa nilai atau kepercayaan tersebut benar. Dampak dari hal tersebut adalah dapat mempengaruhi SoS remaja itu sendiri. Mereka dapat merasa bahwa seolah-olah mereka mengerti dan mengenal nilai-nilai yang mereka anut, padahal nilai tersebut adalah nilai dari kelompok dan belum tentu benar-benar sesuai dengan diri mereka.

Penjelasan di atas memperlihatkan bahwa banyak hal dapat mempengaruhi perilaku dan perkembangan SoS remaja, seperti adolescent egocentrism, personal fable, perkembangan otak (biologis) remaja, ataupun sikap konformitas dalam remaja. Remaja dapat melakukan tindakan bullying karena disebabkan gabungan halhal tersebut, bukan hanya karena satu faktor saja (seperti SoS), karena hal-hal tersebut berada dalam diri remaja dan berpotensi mempengaruhi perilaku remaja.
Beberapa hal tersebut juga
mempunyai kemungkinan dapat mempengaruhi penilaian remaja terhadap SoS mereka. Santrock (2009) menyatakan bahwa remaja termasuk dalam tahap perkembangan SoS dan remaja masih cenderung berubah-ubah. Ketika remaja berhasil menghadapi konflik-konfik selama masa remaja, maka akan terbentuk SoS yang baru dan yang dapat diterima. Hal tersebut memperlihatkan bahwa SoS remaja masih rapuh dan belum terbentuk dengan baik sehingga bisa saja beberapa hal di atas dapat menyebabkan terjadinya bias penilaian remaja terhadap SoS mereka sendiri. Dampak selanjutnya adalah dapat mempengaruhi hasil korelasi antara SoS dengan kecenderungan melakukan bullying pada siswa SMA di Jakarta.

Hasil APRI juga dapat menjadi salah satu alasan tidak terdapat korelasi antara antara SoS dengan kecenderungan melakukan tindakan bullying pada siswa SMA di Jakarta. Remaja sudah dapat berpikir secara lebih logis dibandingkan anak-anak. Mereka sudah mulai dapat berpikir mengenai hipotesis-hipotesis tertentu (Santrock, 2009). Remaja dapat berpikir bahwa item pada APRI berhubungan dengan tindakan negatif di sekolah, sehingga mereka dapat berusaha untuk socially desirable responding (SDR) agar tidak mempunyai image yang jelek. SDR adalah kecenderungan seseorang untuk memberikan jawaban atau respon yang dapat membuat orang tersebut terlihat baik (Paulhus, 1991). Hal tersebut juga mungkin terjadi pada subjek penelitian kali ini. Subjek mengetahui bahwa item yang ada berhubungan dengan perilaku negatif sehingga mereka memberikan jawaban yang dapat membuat subjek terlihat baik.

Hasil penelitian menunjukkan bahwa semakin sedikit nilai APRI maka 
frekuensi dari nilai tersebut cenderung semakin banyak. Hal tersebut memperlihatkan bahwa banyak subjek yang mempunyai nilai rendah sehingga mempunyai kecenderungan yang kecil untuk melakukan tindakan bullying. Nilai rata-rata dari subjek adalah 30.43 dan berarti nilai rata-rata respon item adalah 1.68. Hal tersebut memperlihatkan bahwa rata-rata subjek memberikan respon 1 (tidak pernah) atau 2 (kadang-kadang) pada item yang diberikan yang dapat mempengaruhi nilai total kecenderungan melakukan bullying (cenderung mempunyai nilai rendah). Range nilai hasil APRI juga cenderung lebih kecil bila dibandingkan dengan range nilai hasil SoS, yaitu 20 hingga 44, sedangkan nilai SoS adalah 30 hingga 64. Varians nilai APRI juga lebih kecil jika dibandingkan varians nilai SoS,yaitu 31.470 sedangkan varians nilai SoS adalah 58.53. Hal tersebut memperlihatkan bahwa nilai SoS cenderung lebih beragam dibandingkan nilai APRI. Nilai rendah dan tidak beragam tersebut dapat disebabkan karena memang kecenderungan untuk melakukan tindakan bullying rendah atau karena SDR.

Saran

Hasil penelitian memperlihatkan bahwa tidak ada hubungan antara SoS dengan kecenderungan perilaku bullying pada siswa SMA di Jakarta. Hasil ini diharapkan dapat dijadikan bahan pertimbangan ketika melakukan intervensi. Sekolah atau masyarakat dapat melakukan intervensi yang berfokus pada faktor lain yang dapat mempengaruhi kecenderungan perilaku bullying. Peneliti juga dapat melakukan penelitian yang berfokus pada faktor-faktor lain selain SoS.

\section{DAFTAR PUSTAKA}

Anastasi, A \& Urbina, S. (1997). Psychological Testing (7th ed.). Upper Saddle River: Prentice- Hall, Inc.

Andersen, G. (2007). The impact of bullying in school on the adolescense's sense of self. Disertasi Master. Fakultas Human Science University of Pretoria

Aronson, E., Wilson, T.D., \& Akert, R.M. (2007). Social Psychology (6 ${ }^{\text {th }}$ ed.). New Jersey: Pearson Education, Inc.

Bartlett, J.E., Kotrlik, J.W., \& Higgins, C.C. (2001). Organizational Research: Determining Appropriate Sample Size in Survey Reasearch. Information Technology, Learning, and Performance Journal, 19, 4350 .

Culwell, M.S. (2008). How does a weak versus strong sense of self affect people's social and nonsocial involvement?. Tesis Master. The University of Texas, Arlington

Cynantia. (2012). Bullying dalam dunia pendidikan. Diakses pada 25 Mei 2013 dari stkippasundan.ac.id/2012/11/05/bull ying-dalam-dunia-pendidikan/

Cuperman, R., Robinson, R.L., \& Ickes, W. (2012). On the malleability of self-image in individuals with a weak sense of self. Self and Identitiy, 2012, 1-23.

Darmawan (2010). Bullying in school: a study of forms and motivesof aggressionin two secondary schools 
in the city of Palu, Indonesia. Tesis Master. University of Tromso, Norway

Dinas Pendidikan. (2010). Jumlah siswa Sekolah Menengah Atas (SMA) berdasarkan status sekolah. Diakses pada 20 November 2013 dari Jakarta.go.id/web/bankdata/categor $\mathrm{y} / 7 / 20$

Flurry, J.M., \& Ickes, W. (2007). Having a weak versus strong sense of self: the sense of self scale (soss). [Versi elektronik]. Self and Identity, 6, 281-303.Hasil wawancara dengan salah satu orang SEJIWA tanggal 30 Mei 2013

George, E., Adeoye,A., Ayodele, K.O, \& Raheem, A.I. (2013). The effectiveness of two psycho-social behavioural interventions on adolescents' bullying behaviour among nigerian adolescents. Journal of Studies in Social Sciences, 4, 246-261.

George, E., Ayodele, A., Raheem, A.I., \& Anwanane, B. (2013). Influence of class types and home background and the efficacy of cognitive self instruction on bullying behaviour of nigeria secondary schools students. American Based Research Journal, 2, 33-39.

Ghazemi, A., \& Zahediasl, S. (2012). Normality tests for statistical analysis: a guide for nonstatisticians. [Versi elektronik]. Int J Endocrinol Metab, 10, 486-489.

Hamburger, M.E., Basile, K.C., \& Vivolo, A.M. (Eds.) (2011). Measuring Bullying Victimization,
Perpetration, And Bystander Experiences: A Compendium Of Assessment. Atlanta, GA: Centers for Disease Control and Prevention, National, Center for Injury Prevention and Control Tools.

James, A. (2010). School bullying. Diakses pada 20 Desember 2013 dari nspcc.org.uk/inform/research/briefi ngs/school_bullying_pdf_wdf73502 .pdf

Kaplan, R.M., \& Saccuzzo, D.P. (2009). Psychological Testing: Priciples, Applications, and Issues (7th ed.). USA: Wadsworth, Cangage Learning

Kernis, M. H., et.al. (2000). Master of one's psychological domain? Not likely if one's self esteem is unstable. PSPB, 26, 1297-1305

Kim, S. (2004). A study of personal and environmental factors influencing bullying. Disertasi. Fakultät für Psychologie und Padagogik der Ludwig-Maximilians-Universität

Kothari, C.R. (2004). Research Methodology: Methods \& Techniques. New Delhi: New Age International (P) Ltd., Publishers

Kumar, R. (2005). Research Methodology: A Step by Step Guide for Beginners. London: SAGE publications Inc.Lai, S., Ye, R., \& Chang, K. (2008). Bullying in middles school: an ssian-pacific regional study. Asia Pacific Education Review, 9, 393-405. 
Lai, S., Ye, R., \& Chang, K. (2008). Bullying in middles school: an ssian-pacific regional study. [Versi elektronik]. Asia Pacific Education Review, 9, 393-405.

Levianti. (2008). Konformitas dan bullying pada siswa. Jurnal Psikologi, 6, 1-9.

Macklem, G.L. (2003). Bullying and Teasing: Social Power in Children's Groups. New York: Kluwer Academic/Plenum Publishers

More, I. (2012, 27 Juli). Pelaku "bullying" terancam 5 tahun penjara. Diakses pada 22 November 2013 dari google.com/url? sa $=\mathrm{t} \& \mathrm{rct}=\mathrm{j} \& \mathrm{q}=\&$ es $\mathrm{rc}=\mathrm{s} \&$ source $=$ web $\& \mathrm{~cd}=1 \& \mathrm{cad}=\mathrm{rja}$ $\& v e d=0 \mathrm{CC} 0 \mathrm{QFj} A A \& u r l=h t t p \% 3 \mathrm{~A}$ $\% 2 \mathrm{~F} \% 2 \mathrm{Fmegapolitan}$. kompas.com $\% 2$ Fread $\% 2 \mathrm{~F} 2012 \% 2 \mathrm{~F} 07 \% 2 \mathrm{~F} 27 \%$ 2F1608145\%2FPelaku.Bullying.Ter ancam.5.Tahun.Penjara\&ei=YJ_FU pCTOYTBiQffrIHYDQ\&usg=AFQ jCNFRmn9OgzRWw_OP_Svychjn Kj6jYg

Napitupulu, E.L. (2012, 10 Agustus). Siswa SMA dapat pencerahan antiperundungan. Diakses pada 22 Febuari 2013 dari edukasi.kompas.com/read/2012/08/ 10/13044817/Siswa.SMA.dapat.Pen cerahan.Antiperundungan

Olweus, D. (1993). Bullying at school: what we know and what we can do. Bodmin: Great Britain by Hartnolls

Olweus, D. (1997). Bully/victim problems in school: facts and intervention. [Versi elektronik]. European Journal of Psychology of Education. 12. 495-510.
Paulhus, D.L. (1991). Measurement and Control of Bias. Dalam Robinson, J.P., Shaver, P.R., \& Wrightsman, L.S. (Eds.), Measures Of Personality And Social Psychological Attitudes. (h. 17-59). San Diego, CA: Academic Press, Inc.

Peraturan Pemerintah Republik Indonesia no 66 tahun 2010 diakses pada 31 Oktober 2013 dari unpad.ac.id/wpcontent/uploads/2012/10/PP66-

2010-Pengeloaan Dan Penyelenggaraan Pendidikan.pdf

Prasetyo, A.B.E. (2011). Bullying di sekolah dan dampaknya bagi masa depan anak. [Versi elektronik]. El Tarbawi, 4, 19-26.

Priyatna, A. (2010). Let's End Bullying: Memahami, Mencegah, dan Mengatasi Bullying. Jakarta: PT Elex Media Komputindo

Razali, N.M., \& Wah, Y.B. (2011). Power comparisons of shapiro-wilk, kolmogorov-smirnov, Lilliefors and anderson-darling tests. [Versi Elektronik]. Journal of Statistical Modeling and Analytics, 2, 21-33.

Sanders, C.E \& Phye, G.D. (2004). Bullying: implications for the classroom. USA: Elsevier Academic Press

Santrock, J. W. (2009). Life-Span Development (12th Ed.). New York : McGraw-Hill

SEJIWA. (2008). Penelitian Tentang Kekerasan Di SD, SMP \& SMA Di Indonesia 
Setyowati, E. (2009). Pendidikan budi pekerti menjadi mata pelajaran di sekolah. Lembaran Ilmu Kependidikan, 39, 148-154.

Soeriaatmadja, W. (2011, 25 Juni). Bullying in schools a worry in Indonesia. Diakses pada 28 Oktober 2013 dari thejakartaglobe.com/archive/bullyin g-in-schools-a-worry-in-indonesia/

Suprihatin, I. (2013). Peningkatan motivasi belajar siswa melalui penerapan model pembelajaran curah pendapat (brainstorming) pada mata pelajaran pendidikan kewarganegaraan (PKn) kelas $\mathrm{X}$ IPS 1 di SMAN 6 Semarang tahun ajaran 2013/2014. Skripsi Sarjana. IKIP PGRI, Semarang

Toriq, A. (2012, 31 Juli). Ini bahaya bullying bagi anak-anak. Diakses pada 28 Oktober 2013 dari news.detik.com/read/2012/07/31/09 5616/1979005/10/ini-bahayabullying-bagi-anak-anak

Undang-undang republik Indonesia nomor 20 tahun 2003 tentang sistem pendidikan nasional diakses pada 31 Oktober 2013 dari menkokesra.go.id/node/337

Vally, S. (2005). Corporal punishment and bullying: the rights of learners. Education Rights Project Booklet Series, 11.

Vogels, A. (2012). Healthy Sense of Self: Do You Have What It Takes To Be Yourself?. Bellevue: Healthy Sense Of Self Publications
Whitehouse, P.S. (2006). Bullies and victims from the schoolyard to the boardroom the abridged version. Tesis. University of Denver 